\title{
Aortic Valve Stenosis
}

National Cancer Institute

\section{Source}

National Cancer Institute. Aortic Valve Stenosis. NCI Thesaurus. Code C50462.

Narrowing of the orifice of the aortic valve. 